\title{
Economic Analyses of the Be Fit Be Well Program: A Weight Loss Program for Community Health Centers
}

\author{
Debra P. Ritzwoller, $P h D^{7}$, Russell E. Glasgow, $P h D^{2}$, Anna Y. Sukhanova, $M A^{\text {' }}$, \\ Gary G. Bennett, PhD ${ }^{3,4}$, Erica T. Warner, ScD, Mph ${ }^{5,6}$, Mary L. Greaney, PhD 6 , \\ Sandy Askew, Mph ${ }^{4}$, Julie Goldman, MSW, MPH', Karen M. Emmons, PhD ${ }^{6,7}$, \\ and Graham A. Colditz, Md, DrPH ${ }^{5,8}$ For the Be Fit Be Well Study Investigators
}

\begin{abstract}
'Institute for Health Research, Kaiser Permanente Colorado, Denver, CO, USA; ${ }^{2}$ Division of Cancer Control and Population Sciences, National Cancer Institute, Bethesda, MD, USA; ${ }^{3}$ Department of Psychology and Neuroscience, Duke University, Durham, NC, USA; ${ }^{4}$ Duke Global Health Institute, Duke University, Durham, NC, USA; ${ }^{5}$ Department of Epidemiology, Harvard School of Public Health, Boston, MA, USA; ${ }^{6}$ Center for Community Based Research, Division of Population Sciences, Dana Farber Cancer Institute, Boston, MA, USA; ${ }^{7}$ Department of Society, Human Development and Health, Harvard School of Public Health, Boston, MA, USA; ${ }^{8}$ Division of Public Health Sciences, Department of Surgery, Alvin J. Siteman Cancer Center, Washington University School of Medicine, St Louis, MO, USA.
\end{abstract}

BACKGROUND: The U.S. Preventive Services Task Force has released new guidelines on obesity, urging primary care physicians to provide obese patients with intensive, multi-component behavioral interventions. However, there are few studies of weight loss in real world nonacademic primary care, and even fewer in largely racial/ethnic minority, low-income samples.

OBJECTIVE: To evaluate the recruitment, intervention and replications costs of a 2-year, moderate intensity weight loss and blood pressure control intervention.

DESIGN: A comprehensive cost analysis was conducted, associated with a weight loss and hypertension management program delivered in three community health centers as part of a pragmatic randomized trial.

PARTICIPANTS: Three hundred and sixty-five high risk, low-income, inner city, minority (71\% were Black/African American and $13 \%$ were Hispanic) patients who were both hypertensive and obese.

MAIN MEASURES: Measures included total recruitment costs and intervention costs, cost per participant, and incremental costs per unit reduction in weight and blood pressure.

KEY RESULTS: Recruitment and intervention costs were estimated $\$ 2,359$ per participant for the 2-year program. Compared to the control intervention, the cost per additional kilogram lost was $\$ 2,204 / \mathrm{kg}$, and for blood pressure, $\$ 621 / \mathrm{mmHg}$. Sensitivity analyses suggest that if the program was offered to a larger sample and minor modifications were made, the cost per participant could be reduced to the levels of many commercially available products.

CONCLUSIONS: The costs associated with the Be Fit Be Well program were found to be significantly more expensive than many commercially available products, and much higher than the amount that the Centers for

Trial Registration: clinical trials.gov Identifier: NCTOO661817

Received July 3, 2012

Revised January 4, 2013

Accepted April 17, 2013

Published online June 4, 2013
Medicare and Medicaid reimburse physicians for obesity counseling. However, given the serious and costly health consequences associated with obesity in high risk, multimorbid and socioeconomically disadvantaged patients, the resources needed to provide interventions like those described here may still prove to be costeffective with respect to producing long-term behavior change.

KEY WORDS: weight loss; RCT; pragmatic trial; cost; cost-effectiveness; health disparities.

J Gen Intern Med 28(12):1581-8

DOI: $10.1007 / \mathrm{s} 11606-013-2492-3$

(c) Society of General Internal Medicine 2013

\section{INTRODUCTION}

The U.S. Preventive Services Task Force (USPSTF) recently released updated obesity guidelines that have the potential to provide the impetus for the U.S. primary care system to adequately address preventing, reducing, and managing the consequences of obesity. ${ }^{1}$ However, evidence-based weight management strategies have not proven sustainable in realworld clinical practice, and few published primary care-based obesity treatment trials have yielded clinically significant, longterm outcomes. ${ }^{2-5}$ Evidence is particularly lacking for moderate intensity interventions, that may ultimately have the greatest potential for widespread reach and adoption in low-resource settings. ${ }^{6}$ Furthermore, although behavioral and clinical hypertension management strategies have been widely tested and disseminated, hypertension control rates remain sub-optimal, particularly for medically vulnerable and obese patients. ${ }^{7,8}$

Patients who receive care in community health centers (CHCs) are particularly impacted by the limited availability of practical, evidence based obesity treatments. These patients have high rates of obesity ${ }^{9,10}$ and obesity-associat- 
ed conditions, ${ }^{11-14}$ particularly hypertension and cardiovascular disease, ${ }^{15}$ and have been underrepresented in obesity trials. Evidence-based weight loss strategies are less effective in these populations. ${ }^{16-19}$ Finally, very little is known about the costs and cost-effectiveness (CE) of weight loss interventions for low-income populations.

We previously reported the findings from a pragmatic randomized controlled trial ${ }^{20,21}$ that demonstrated the effectiveness of a 2-year behavioral intervention that produced modest weight losses and improved blood pressure control among socioeconomically disadvantaged, high risk, primary care patients who receive care in $\mathrm{CHCs} .{ }^{22,23}$ The Be Fit Be Well (BFBW) intervention is described in detail elsewhere, ${ }^{22,23}$ and was based on the RE-AIM framework, along with evidence-based eHealth technology approaches designed for population reach and implementation in resource poor settings and for low-literacy, inner city patients. ${ }^{24,25}$ The primary aim of this paper is to illustrate comprehensive and transparent costing methods, and to report costs for implementation and replication purposes associated with the BFBW intervention. The secondary aim is to estimate the costs of the program under different conditions and assumptions. ${ }^{26,27}$

\section{METHODS AND PROCEDURES}

\section{Study Design}

As described in detail elsewhere, ${ }^{22,23}$ the BFBW study was a two-arm, 24-month patient-randomized pragmatic trial conducted among 365 obese adult primary care patients with hypertension. The BFBW intervention was an evidence-based, moderate intensity, pragmatic intervention, ${ }^{28,29}$ designed to produce weight loss through the modification of obesogenic lifestyle behaviors. Participants received tailored behavior change goals and tailored "prescriptions" for weight-related behavior changes signed by their provider. Participants selfmonitored their adherence to those goals via their choice of Internet or automated telephone based reporting systems. Community health educators (CHEs) facilitated the intervention via 18 counseling phone calls and optional group meetings. All study protocols were fully approved by the Harvard School of Public Health institutional review board.

Participants were recruited between February 2008 and April 2009, from three urban CHCs that serve a predominately racial/ethnic minority patient population in Boston. Participants were required to have a body mass index (BMI) between 30 and $50 \mathrm{~kg} / \mathrm{m}^{2}$ and a weight less than $180 \mathrm{~kg}$, use of one or more antihypertensive medication, be at least 21 years old, and have one or more medical visits in the 12 months before study entry and willingness to provide written informed consent. As noted in the CONSORT diagram in Fig. 1, 180 subjects were randomized to the BFBW intervention arm and 185 to Usual Care (UC). Recruitment, participation rates, reasons for declining recruitment, and more detailed description of participant characteristics are presented in detail in Bennett et al. ${ }^{23}$ As shown in Table 1, the sample was low-income, largely African American or Latino, and had other chronic conditions in addition to obesity and hypertension.

\section{Recruitment and Intervention Activities}

Recruitment. Research staff conducted medical chart reviews to identify potential participants, and as described in Greaney et al., ${ }^{22}$ recruiting and enrolling 365 subjects into the BFBW program required multiple phone calls and contacts by bilingual project staff and an off-site call center, as well as several trips to the CHCs. Staff resources were also used to contact primary care physicians for approval of participants with a history of diabetes or cardiovascular disease.

Intervention. Intervention activities associated with the BFBW program were primarily associated with eHealth technology monitoring and support, print support materials, mailing supplies, and the personnel needed for counseling calls and group sessions. BFBW eHealth technology options included the study website and interactive voice response (IVR) systems. Participants picked intervention modality - either web or print plus IVR. The print plus IVR condition allowed participants to track their behavioral goals on a paper log and enter information weekly via IVR. Both systems tracked participant use and provided real-time tailored feedback associated with participants' goals and self-monitoring data.

Community health educators (CHEs) were hired and trained in principles of motivational interviewing, and were certified at baseline, re-certified annually, and received weekly supervision throughout the study. The CHEs role included providing 18 counseling calls - monthly the first year of the intervention, then bi-monthly the second year. Each call lasted approximately 15-20 min. Consistent with the protocol, research staff could make up to 14 attempts to contact each participant over a 2-week period. An optional 90-minute group session was offered bi-monthly (12 in total over a 2-year period), facilitated by one of the trained study CHEs.

Usual Care. Participants in the UC arm of the intervention received the "Aim for a Healthy Weight" self-help booklet ${ }^{30}$ that is available without charge, to individuals and clinicians. No other study resources were directed toward the UC arm.

\section{Clinical Outcome Measures}

Change in body weight $(\mathrm{kg})$ was the primary outcome; change in systolic blood pressure (SBP; $\mathrm{mmHg}$ ) was considered a secondary outcome. Complete descriptions of the trial design and results are published in Greaney et al. ${ }^{22}$ 


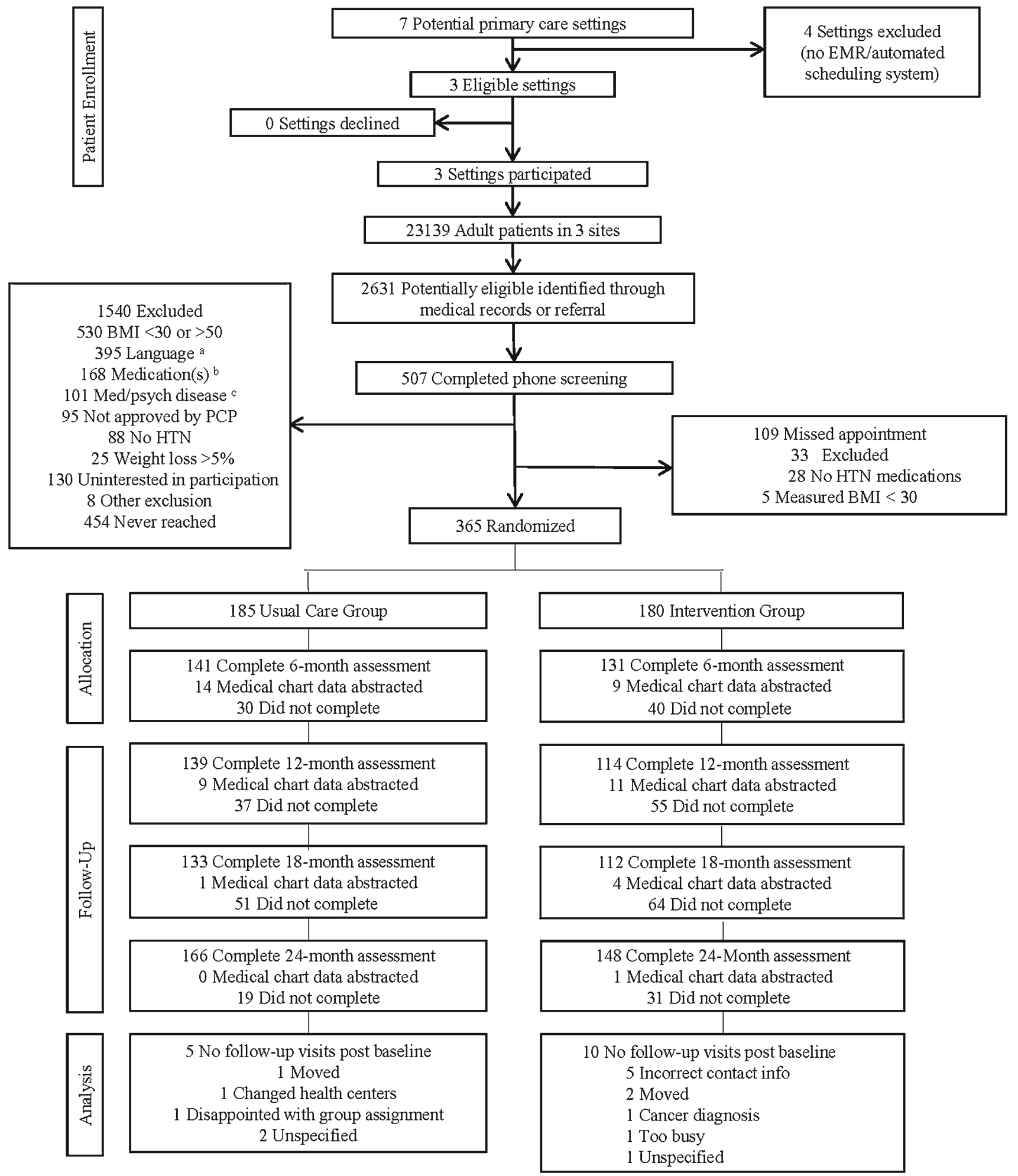

a Non-English or Spanish speakers; b Chronic use of medications likely to cause weight gain or prevent weight loss c Participants excluded due to a serious medical condition or psychiatric condition

Figure 1. CONSORT flow diagram.

and Bennett et al. ${ }^{23}$ In brief, trained research staff administered a computer-based questionnaire and collected anthropometric and blood pressure measurements at baseline and $6,12,18$, and 24 months post-baseline, and intent- 
Table 1. Participants' Baseline Characteristics

\begin{tabular}{lll}
\hline Characteristic & $\begin{array}{l}\text { Usual care } \\
(\boldsymbol{N = 1 8 5 )}\end{array}$ & $\begin{array}{l}\text { Intervention } \\
(\boldsymbol{N = 1 8 0 )}\end{array}$ \\
\hline Male (\%) & $34.1 \%$ & $28.9 \%$ \\
Race/ethnicity (\%) & & \\
White & $2.2 \%$ & $5.0 \%$ \\
African American & $70.8 \%$ & $71.7 \%$ \\
Hispanic & $12.4 \%$ & $13.9 \%$ \\
Other & $14.6 \%$ & $9.4 \%$ \\
Age (years; mean \pm s.d.) & $54.7 \pm 11.0$ & $54.6 \pm 10.8$ \\
Bachelors'degree or higher (\%) & $10.8 \%$ & $16.7 \%$ \\
Income of $\geq \$ 50,000$ (\%) & $12.4 \%$ & $18.3 \%$ \\
Employed (\%) & $53.0 \%$ & $52.2 \%$ \\
Receiving medicaid (\%) & $31.3 \%$ & $36.1 \%$ \\
Weight (kg; mean \pm s.d.) & $100.6 \pm 18.7$ & $99.7 \pm 16.3$ \\
BMI (kg/m ; mean \pm s.d.) & $37.0 \pm 5.2$ & $37.0 \pm 5.0$ \\
SBP (mm Hg; mean \pm s.d.) & $128.5 \pm 19.8$ & $130.2 \pm 18.9$ \\
DBP (mmHg; mean \pm s.d.) & $77.5 \pm 13.8$ & $79.3 \pm 12.7$ \\
\hline
\end{tabular}

SBP systolic blood pressure; DBP diastolic blood pressure; BMI body mass index

to-treat analyses were used to assess the mean difference in weight and SBP between treatment arms at 24 months, after adjusting for gender and health center. As described in detail elsewhere (http://archinte.jamanetwork.com/data/ Journals/INTEMED/23009/IOI120001_supp.pdf), after adjusting for sex and health center, changes in outcomes were estimated with mixed effects regression models. All 365 participants are included in the primary outcomes analysis, including 15 (4\%) participants who only had a baseline assessment. Participants with missing visits are treated as missing at random. We also compared the difference in weight and SBP over the 24-month study period between arms, estimated by the area under the curve (AUC) defined by: AUC = mean (all available weights at 6-, 12-, 18-, and 24-months) minus baseline weight. ${ }^{31}$

\section{Personnel Cost Measures}

Using methods employed in several of our previous studies, and consistent with an activity accounting model method, ${ }^{32}$ we created a detailed accounting system that captured all implementation - and recruitment - attributable costs for the 24-month long BFBW program. ${ }^{26,27,33}$ Consistent with instruments described in Ritzwoller et al., ${ }^{26}$ tailored costcapture templates that were based on study staff responsibilities and relevant task categories were used to capture personnel time. The staff edited or altered these templates to capture the tasks in which they were involved, and these tasks were recorded as hours spent by each individual staff member. Data from the templates were updated and analyzed monthly. To establish consistency in wage rates across different sites, we utilized 2009 data from the Bureau of Labor Statistics (BLS). ${ }^{34}$ Work units were recorded as hours, and were transformed into the corresponding dollar amounts based on a unit cost measure of hourly wages derived from the specific job classification of each staff person (e.g., community health educator, administrative assistant, etc.) and type of task the staff person was performing (e.g., telephone calls, emails, etc.). Labor cost estimates also included a $33 \%$ fringe benefit rate.

\section{Non-Personnel Cost Measures}

We tracked other intervention-related expenses, including for mailing supplies, printing materials (including translation costs), and other project-related costs. We excluded expenses that dealt with development of the intervention interactive voice response (IVR) and website systems, assessment and data collection, and other research-related activities that would not be replicated if the study were continued at the CHCs or implemented in another setting.

\section{Recruitment and Intervention Cost Estimation}

We estimated costs from a CHC perspective. Using 2009 wages and prices, we estimated total recruitment and intervention costs, excluding any captured costs related to development or research. Given that no intervention resources were directed toward the UC condition, incremental intervention costs associated with all months of the BFBW program relative to $\mathrm{UC}$ were considered to be the intervention related costs. We calculated the costs per participant and estimated the marginal costs of the BFBW program per incremental improvement in the weight and blood pressure outcomes from the trial results as reported by Bennett et al. ${ }^{23}$

\section{Varied Assumptions}

Based on observations from the trial associated with plausible changes to the program ${ }^{23}$ that could be employed in other settings, we recalculated the costs with the following alternative assumptions: use of electronic medical records to identify potentially eligible obese patients with hypertension (reduction in recruitment costs), increasing the intervention population from 180 to 5,000 participants, and dropping the optional group sessions (due to the low attendance rate of participants). We did not consider dropping other intervention components because we cannot predict how doing so could impact outcomes.

\section{RESULTS}

\section{Recruitment and Intervention Costs}

Table 2 provides details of recruitment, and intervention costs associated with the BFBW program. The overall costs for the 2-year long intervention program were $\$ 424,624$ or 
Table 2. Be Fit Be Well Recruitment and Intervention Costs by Category

\begin{tabular}{|c|c|c|c|}
\hline \multicolumn{4}{|c|}{ Project cost components } \\
\hline Recruitment & Cost & Intervention & Cost \\
\hline Letters & $\$ 2,955$ & CHE training & $\$ 24,669$ \\
\hline Phone calls & $\$ 6,723$ & CHE supervision & $\$ 5,905$ \\
\hline Chart review & $\$ 4,006$ & Administrative tasks & $\$ 45,247$ \\
\hline Meetings & $\$ 1,457$ & Budget administration & $\$ 7,655$ \\
\hline Travel & $\$ 5,818$ & E-mails & $\$ 47,624$ \\
\hline $\begin{array}{l}\text { Data entry/ } \\
\text { e-mails }\end{array}$ & $\$ 4,097$ & Clinic interviews & $\$ 8,560$ \\
\hline \multirow[t]{8}{*}{ Overhead } & $\$ 6,644$ & $\begin{array}{l}\text { Staff meetings and } \\
\text { intervention preparation }\end{array}$ & $\$ 70,543$ \\
\hline & & Document preparation & $\$ 17,883$ \\
\hline & & Document translation & $\$ 8,174$ \\
\hline & & Print materials \& mailings & $\$ 5,591$ \\
\hline & & Participant phone calls & $\$ 71,265$ \\
\hline & & Participant support group & $\$ 6,947$ \\
\hline & & eHealth technology & $\$ 32,499$ \\
\hline & & Other intervention related & $\$ 40,362$ \\
\hline $\begin{array}{l}\text { Total recruitment } \\
\text { costs }\end{array}$ & $\$ 31,700$ & Total intervention costs & $\$ 392,924$ \\
\hline Total recruitment & . & n costs $=\$ 424,624$ & \\
\hline
\end{tabular}

an average of $\$ 2,354$ per intervention participant $(\$ 2,182$ excluding recruitment costs). Recruitment costs amounted to over $\$ 31,700$ or about $8 \%$ of the overall costs. The primary source of recruitment costs were overhead (cost not directly attributable to patient contacts), phone calls to potential participants - including missed phone calls - and travel time to and from the community health centers, respectively.

The primary costs for delivering the intervention came from labor costs of participant phone calls, totaling $\$ 71,265$. The next most expensive cost category was for project related meetings and intervention preparation $(\$ 70,543)$, which included a significant amount of time with community health center staff. Printed material was a significant component of the intervention, but comprised only $\$ 5,591$ in project related costs.

It was challenging to accurately estimate the computer and IVR costs for the project, partially because the Webbased program was largely adapted from prior work; ${ }^{28}$ and the fact that the IVR contract included costs for piloting, implementation, quality control, data transfer and overhead costs that did not vary by the number of users. We conservatively estimated that only the latter three categories would be needed for replication of the intervention, so the combined eHeath Technology cost (for both Web and IVR) was estimated at $\$ 32,499$.

\section{Primary Outcomes and Costs}

The primary intervention results are summarized in Table 3 and presented in detail in the main outcome paper. ${ }^{23}$ In brief, the intervention was moderately, but significantly more effective than the usual care condition for both primary outcome of weight loss and secondary outcome of blood pressure reduction. Intervention participants had greater 24-month weight losses compared to those receiving usual care (difference: $-1.03 \mathrm{~kg} ; 95 \%$ CI $-2.03,-0.03$ ). Additionally, the intervention promoted larger mean weight losses over 24 months relative to usual care (AUC difference: $-1.07 \mathrm{~kg}(95 \% \mathrm{CI}-1.94,-0.22)$. With respect to blood pressure changes, in AUC analyses including data from months 12 through 24, intervention participants had larger mean SBP changes than usual care (AUC difference: $-3.8 \mathrm{mmHg} ; 95 \% \mathrm{CI}-6.9,-0.7)$, but not DBP $(-0.1 \mathrm{mmHg} ; 95 \% \mathrm{CI}-2.9,1.1)$. Employing an intent-totreat perspective, and including only intervention costs, as noted in Table 4, the incremental cost per $\mathrm{kg}$ lost at 24 months was $\$ 2,040$ per $\mathrm{kg}$ and $\$ 574$ per $\mathrm{mmHg}$ of systolic blood pressure reduction.

\section{Costs Under Alternative Assumptions}

Estimates of the costs per participant were found to vary, depending upon several factors, including recruitment methods, the number of targeted participants, and the exclusion of the optional group session. If eligible participants could be identified via electronic registries, we could eliminate the chart reviews and substantially reduce recruitment related letters and phone calls. Based on other projects involving electronic registries, ${ }^{26,33}$ we estimate it would take approximately $20 \mathrm{~h}$ of programmer time for data extraction and cleaning, for a total cost of $\$ 718$. Recruitment costs could then be reduced by $29 \%$ or by $\$ 22,522$. If the optional group sessions were dropped, intervention costs would only decrease by less than $2 \%$. However, if we assume fixed costs associated with the eHealth technology component of the intervention, and economies of scale (i.e., they are not at capacity) across the other intervention inputs, we estimate that we could increase the number of participants to 5,000 , for a total intervention cost of $\$ 2,183,000$, or a reduction in per participant costs from $\$ 2,183$ to $\$ 437$.

\section{DISCUSSION}

The primary purpose of this article was to calculate the costs and the potential cost-effectiveness of the BFBW program, designed for a low literacy, inner city $\mathrm{CHC}$ population with obesity and hypertension. Cost is often the first question that potential adopters in low resource settings ask, and if the answer is not acceptable, the discussion often stops. A closely related question concerns the amount of staff and resource demands that a program makes. We documented several costs frequently omitted by many reports, but incurred by those who would adopt such 
Table 3. Baseline Levels and Weight and Blood Pressure Changes by Treatment Group

\begin{tabular}{|c|c|c|c|c|c|c|}
\hline & No. & $\begin{array}{l}\text { Baseline } \\
\text { Mean (SD) }\end{array}$ & $\begin{array}{l}\text { Month 12 } \\
\text { Mean (SD) }\end{array}$ & $\begin{array}{l}\text { Month } 24 \\
\text { Mean (SD) }\end{array}$ & $\begin{array}{l}\mathrm{AUC}^{*} \\
\text { (SD) }\end{array}$ & Slope per year \\
\hline \multicolumn{7}{|l|}{ Mean (SE) weight change $(\mathrm{kg})$} \\
\hline Usual care & 185 & $100.61(18.67)$ & $-0.32(0.36)$ & $-0.5(0.35)$ & $-0.33(0.30)$ & \\
\hline Intervention & 180 & $99.70(16.29)$ & $-1.37(0.38)$ & $-1.53(0.37)$ & $-1.41(0.30)$ & \\
\hline $\begin{array}{l}\text { Mean difference between } \\
\text { arms }(95 \% \mathrm{CI})\end{array}$ & & & $-1.05(-2.09,-0.01)$ & $-1.03(-2.03,-0.03)$ & $-1.07(-1.94,-0.22)$ & \\
\hline \multicolumn{7}{|l|}{ Mean (SE) SBP change } \\
\hline Usual care & 185 & $128.55(19.73)$ & $3.35(1.56)$ & $5.30(1.47)$ & $4.34(1.02)$ & $1.23(1.80)$ \\
\hline Intervention & 180 & $130.22(18.89)$ & $-1.38(1.68)$ & $1.56(1.54)$ & $1.84(1.06)$ & $0.07(1.61)$ \\
\hline Mean difference $(95 \% \mathrm{CI})$ & & & $-4.73(-9.23,-0.22)$ & $-3.73(-7.91,0.45)$ & $-2.50(-5.40,0.40)$ & $\begin{array}{l}-1.16(-2.12,-0.20) \\
P=0.02\end{array}$ \\
\hline \multicolumn{7}{|l|}{ Percentage with BP control } \\
\hline Usual care & 185 & 74.59 & 64.75 & 58.43 & & $0.34(0.10)^{\dagger}$ \\
\hline Intervention & 180 & 62.78 & 71.93 & 64.63 & & $0.14(0.12)$ \\
\hline $\mathrm{OR}^{\dagger}$ & & 0.57 & 1.39 & 1.52 & & Difference: -0.21 \\
\hline$(95 \% \mathrm{CI})$ & & $(0.37,0.90)$ & $(0.98,1.98)$ & $(1.01,2.30)$ & & $\begin{array}{l}(-0.41,0.00) \\
P=0.05\end{array}$ \\
\hline
\end{tabular}

"AUC = mean (all available weights or BPs at 6, 12, 18, 24 months) minus baseline weight/BP, adjusting for baseline weight/BP, gender and clinic tSlope in log odds of \% BP control per year adjusting for gender and clinic

*Adjusted for baseline BP control, gender and clinic

programs, including costs of recruitment, training, delivery, supervision, travel, equipment, supplies, unsuccessful phone call attempts, etc. We estimated costs from the perspective of potential adopting clinics because these are the settings most likely to adopt - and pay for - an intervention such as BFBW. The BFBW program was designed to be efficient and minimally disruptive to primary care, and to leverage the $\mathrm{CHC}$ and patient relationships - primarily through ongoing contacts with CHEs. As described elsewhere, the program proved feasible in attracting a relatively high percentage of eligible patients, engaging them in the largely technology based intervention, and producing more weight loss and SBP reduction than the control condition. ${ }^{23}$

Compared to other published literature related to the costs and cost-effectiveness of obesity treatment programs, the intervention costs of the BFBW appear to be relatively high. The estimated \$2,040 per kg lost associated with the BFBW program is much higher than estimates of the three major commercial programs that have been evaluated in randomized studies-Jenny Craig ${ }^{\circledR}$ at $\$ 289-\$ 383$ per kg, Nutrisystem $^{\circledR} \$ 286-\$ 306$ per kg, and Weight Watchers ${ }^{\circledR}$ at $\$ 214$ per kg. ${ }^{35}$ However, none of these evaluations targeted

Table 4. Per-Participant Costs and Costs Per Unit Change in Weight and Systolic Blood Pressure

\begin{tabular}{lll}
\hline & $\begin{array}{l}\text { Incremental } \\
\text { recruitment and } \\
\text { intervention costs }\end{array}$ & $\begin{array}{l}\text { Incremental } \\
\text { intervention (only) } \\
\text { costs }\end{array}$ \\
\hline $\begin{array}{l}\text { Be Fit Be Well } \\
\text { participant }\end{array}$ & $\$ 2,359$ & $\$ 2,182$ \\
$\begin{array}{l}\text { Outcome: } \\
\text { Weight loss (kg) }\end{array}$ & $\$ 2,204$ & $\$ 2,040$ \\
$\begin{array}{c}\text { Systolic blood } \\
\text { pressure (mm Hg) }\end{array}$ & $\$ 621$ & $\$ 574$ \\
\hline
\end{tabular}

minority or socioeconomically disadvantaged populations or used 2-year outcomes. ${ }^{36,37}$ While several internet-based studies have estimated lower cost per participant those estimated for BFBW, the targeted populations, the length of the intervention, and the methods used to estimate intervention costs differed significantly from this study. ${ }^{37-41}$ In addition, the 2-year per-capita direct cost estimate associated with the Diabetes Prevention Program (DPP) lifestyle intervention (not including recruitment) was estimated in year 2000 dollars at $\$ 2,078 .^{41}$ This value is not inconsistent with our BFBW per-participant estimated costs in 2009 dollars, as noted in Table 4, of $\$ 2,182$. Employing a basic Consumer Price Index adjustment (http://www.bls.gov/cpi/ \#tables), in 2009 dollars, the DPP per capita cost is estimated at $\$ 2,563$. Our cost estimates are likely more comprehensive than those of most other behavioral intervention cost reports ${ }^{26,37-39,41}$ because we closely monitored resources as the intervention program was delivered, rather than employing retrospective surveys ${ }^{41}$ and included training, supervision and recruitment costs.

In November 2011, Medicare began reimbursing physicians \$528-\$748 (depending on geographic area) for up to 22 physician visits over a 12 -month period (conditional on a $3 \mathrm{~kg}$ weight loss in the first 6 months) for intensive behavioral obesity counseling services. ${ }^{42}$ However, the uptake and outcomes associated with this new covered benefit are unknown. In sum, the overall costs of $\$ 2,182$ per participant for a two-year long intervention may be necessary, given the obesogenic environment and the intransigence of the obesity problem among such complex patients. ${ }^{43}$

It is unclear whether or not the costs of BFBW could be reduced to levels that are competitive with commercial programs, yet still allow for the engagement of target 
populations with characteristics similar to those in BFBW. From the alternative assumptions based analyses noted above, if future implementation strategies could produce cost reductions through economies of scale, a focus on eHealth technologies, and the elimination of the optional group session, it may be possible to have costs approaching those of commercial programs. For health care centers where electronic medical records or registries are available to track subjects with elevated BMIs and blood pressures, additional cost savings could be found.

Limitations of this report include the absence of costs from the participant perspective,${ }^{44}$ the absence of capture of medical care utilization and costs during the intervention period, that the absolute weight loss was modest, and the study was that results are limited to three community health centers in one inner city setting. Nevertheless, given the high risk of these patients, the duration of the program, the encouraging results on blood pressure, as well as the appeal and feasibility of the intervention, the BFBW program is worth further evaluation in different settings and conditions. Strengths of the report include the practical randomized design, ${ }^{29}$ the intervention settings and population, the 24-month follow-up evaluation, and the inclusion of sensitivity analyses and transparent, comprehensive costing procedures. In conclusion, in light of the recent USPSTF recommendation that clinicians offer intensive multi-component behavioral interventions to obese patients with a BMI of $30 \mathrm{~kg} / \mathrm{m} 2$ or higher, we suggest that BFBW could be an excellent "minimal intervention needed for change" $" 45$ that could be implemented.

Acknowledgements: We would like to thank Barbara L. McCray for her editorial support.

Funding/Support: This work was supported in part by grant funding from the National Heart Lung Blood Institute (UO1HL087071). G. Bennett was supported by K22CA126992.

K. Emmons was supported by K05CA124415-04. G. Colditz was supported in part by P30CA091842 and the Foundation for BarnesJewish Hospital. E. Warner was supported by grant 5T32CA009001-36 from the National Cancer Institute.

Disclaimer: The opinions and statements in this manuscript do not represent the official opinion of NHLBI/ NCI/NIH.

Conflict of Interest: The authors declare that they do not have a conflict of interest.

Corresponding Author: Debra P. Ritzwoller, PhD; Institute for Health Research, Kaiser Permanente Colorado, P.O. Box 378066 , Denver, CO 80237-8066, USA (e-mail: Debra.Ritzwoller@kp.org).

\section{REFERENCES}

1. Moyer VA, on behalf of the U.S. Preventive Services Task Force Screening for and management of obesity in adults: U.S. Preventive Services Task Force recommendation statement. Ann Intern Med. 2012;157:373-8.
2. Stafford RS, Farhat JH, Misra B, et al. National patterns of physician activities related to obesity management. Arch Fam Med. 2000;9:631-8.

3. Ma J, Xiao L, Stafford RS. Underdiagnosis of obesity in adults in US outpatient settings. Arch Intern Med. 2009;169:313-4.

4. Galuska DA, Will JC, Serdula MK, et al. Are health care professionals advising obese patients to lose weight? JAMA. 1999;282:1576-8.

5. Bleich SN, Pickett-Blakely O, Cooper LA. Physician practice patterns of obesity diagnosis and weight-related counseling. Patient Educ Couns. 2011;82:123-9.

6. Glasgow RE. What types of evidence are most needed to advance behavioral medicine? Ann Behav Med. 2008;35:19-25.

7. Svetkey LP, Pollak KI, Yancy WS Jr, et al. Hypertension improvement project: randomized trial of quality improvement for physicians and lifestyle modification for patients. Hypertension. 2009;54:1226-33.

8. Bosworth HB, Olsen MK, Neary A, et al. Take Control of Your Blood Pressure (TCYB) study: a multifactorial tailored behavioral and educational intervention for achieving blood pressure control. Patient Educ Couns. 2008;70:338-47.

9. Ogden CL, Lamb MM, Carroll MD, et al. Obesity and socioeconomic status in adults: United States, 2005-2008. NCHS Data Brief 2010;1-8.

10. Flegal KM, Carroll MD, Ogden CL, et al. Prevalence and trends in obesity among US adults, 1999-2008. JAMA. 2010;303:235-41.

11. Karlamangla AS, Merkin SS, Crimmins EM, et al. Socioeconomic and ethnic disparities in cardiovascular risk in the United States, 20012006. Ann Epidemiol. 2010;20:617-28.

12. Winkleby MA, Kraemer HC, Ahn DK, et al. Ethnic and socioeconomic differences in cardiovascular disease risk factors: findings for women from the Third National Health and Nutrition Examination Survey, 19881994. JAMA. 1998;280:356-62.

13. McGruder HF, Malarcher AM, Antoine TL, et al. Racial and ethnic disparities in cardiovascular risk factors among stroke survivors: United States 1999 to 2001. Stroke. 2004;35:1557-61.

14. Roger VL, Go AS, Lloyd-Jones DM, et al. Heart disease and stroke statistics-2011 update: a report from the American Heart Association. Circulation. 2011;123:e18-209.

15. Redmond N, Baer HJ, Hicks LS. Health behaviors and racial disparity in blood pressure control in the national health and nutrition examination survey. Hypertension. 2011;57:383-9.

16. Osei-Assibey G, Kyrou I, Adi Y, et al. Dietary and lifestyle interventions for weight management in adults from minority ethnic/non-White groups: a systematic review. Obes Rev. 2010;11:769-76.

17. Yancey AK, Kumanyika SK, Ponce NA, et al. Population-based interventions engaging communities of color in healthy eating and active living: a review. Prev Chron Dis. 2004;1:A09.

18. Kumanyika SK, Gary TL, Lancaster KJ, et al. Achieving healthy weight in African-American communities: research perspectives and priorities. Obes Res. 2005; 13:2037-47.

19. Kumanyika SK, Obarzanek E, Stevens VJ, et al. Weight-loss experience of black and white participants in NHLBI-sponsored clinical trials. Am J Clin Nutr. 1991;53:1631S-8.

20. Tunis SR, Stryer DB, Clancey CM. Practical clinical trials: increasing the value of clinical research for decision making in clinical and health policy. JAMA. 2003;290:1624-32. PMID 14506122.

21. Zwarenstein $\mathbf{M}$, Treweek $\mathbf{S}$, Gagnier JJ, et al. Improving the reporting of pragmatic trials: an extension of the CONSORT statement. BMJ. 2008;337:a2390. doi:10.1136/bmj.

22. Greaney ML, Guintiliani LM, Warner ET, et al. Weight management among patients at community health centers: the Be Fit Be Well Study. Obes Weight Manag. 2009;5(5):222-8.

23. Bennett GG, Warner ET, Glasgow RE, et al. Obesity treatment for socioeconomically disadvantaged patients in primary care practice. Arch Intern Med. 2012;172:565-74.

24. Glasgow RE. Enhancing the scientific foundation of internet intervention research. Ann Behav Med. 2009;38:46-7.

25. Glasgow RE, Vogt TM, Boles SM. Evaluating the public health impact of health promotion interventions: the RE-AIM framework. Am J Public Health. 1999;89:1322-7.

26. Ritzwoller DP, Sukhanova A, Gaglio B, et al. Costing behavioral interventions: a practical guide to enhance translation. Ann Behav Med. 2009;37:218-27.

27. Ritzwoller DP, Sukhanova AS, Glasgow RE, et al. Intervention costs and cost-effectiveness for a multiple-risk-factor diabetes self-management trial for Latinas: economic analysis of ¡Viva Bien! Transl Behav Med. 2011;1:427-35.

28. Bennett GG, Herring SJ, Puleo E, et al. Web-based weight loss in primary care: a randomized controlled trial. Obesity (Silver Spring). 2010;18:308-13. 
29. Glasgow RE, Gaglio B, Bennett G, et al. Applying the PRECIS criteria to describe three effectiveness trials of weight loss in obese patients with comorbid conditions. Health Serv Res. 2012;47(3 Pt 1):1051-67.

30. National Heart Lung and Blood Institute. Aim for a health weight. Available at: http://www.nhlbi.nih.gov/resources/obesity/education/ aim.htm. 2012. Accessed February 9, 2012.

31. Rosner B, Langford HG. Judging the effectiveness of antihypertensive therapy in an individual patient. J Clin Epidemiol. 1991;44:831-8.

32. Frick KD. Microcosting quantity data collection methods. Med Care. 2009;47:S76-81.

33. Sukhanova A, Ritzwoller DP, Alexander G, et al. Cost analyses of a web-based behavioral intervention to enhance fruit and vegetable consumption. Int J Behav Nutr Phys Act. 2009;6:92.

34. Bureau of Labor Statistics. Occupational employment and wages-May 2009. Available at: http://www.bls.gov/oes/2009/may/oes_nat.htm. 2010. Accessed April 23, 2013.

35. CNN Money. Slim your body, not your wallet. Available at: http:// money.cnn.com/2011/06/03/pf/weight_loss_programs.moneymag/ index.htm. 2011. June 3. Accessed April 23, 2013.

36. Tsai AG, Wadden TA. Systematic review: an evaluation of major commercial weight loss programs in the United States. Ann Intern Med. 2005; 142:56-66.

37. Rasu RS, Hunter CM, Peterson AL, et al. Economic evaluation of an Internet-based weight management program. Am J Manag Care. 2010;16:e98-104.
38. Gustafson A, Khavjou O, Stearns SC, et al. Cost-effectiveness of a behavioral weight loss intervention for low-income women: the WeightWise Program. Prev Med. 2009;49:390-5.

39. Krukowski RA, Tilford JM, Harvey-Berino J, et al. Comparing behavioral weight loss modalities: incremental cost-effectiveness of an internet-based versus an in-person condition. Obesity (Silver Spring). 2011;19:1629-35.

40. Tate DF, Finkelstein EA, Khavjou O, et al. Cost effectiveness of internet interventions: review and recommendations. Ann Behav Med. 2009;38:40-5.

41. Herman WH, Brandle M, Zhang P, et al. Costs associated with the primary prevention of type 2 diabetes mellitus in the Diabetes Prevention Program. Diabetes Care. 2003;26:36-47.

42. Department of Health and Human Services, Centers for Medicare \& Medicaid Services, MLN Matters. Intensive Behavioral Therapy (IBT) for obesity. Available at: http://www.cms.gov/Outreach-and-Education/ Medicare-Learning-Network-MLN/MLNMattersArticles /downloads / MM7641.pdf. 2011. Accessed April 23, 2013.

43. Gearhardt AN, Bragg MA, Pearl RL, et al. Obesity and public policy. Annu Rev Clin Psychol. 2012;8:405-30.

44. Gold MR, Siegel JE, Russell LB, Weinstein MC. Cost-Effectiveness in Health and Medicine. Oxford, England: Oxford University Press; 1996.

45. Glasgow RE, Steiner JF. In: Brownson RC, Colditz G, Proctor E, eds. Comparative Effectiveness Research to Accelerate Translation: Recommendations for "CERT-T". 1st ed. New York: Oxford University Press; 2012:72-93. 